\title{
O SISTEMA PRICE E A CONTROVÉRSIA JURÍDICA: DISCUSSÕES SOBRE UMA EDUCAÇÃO FINANCEIRA PARA A MATEMÁTICA NA EDUCAÇÃO BÁSICA
}

\author{
PRICE SYSTEM AND LEGAL CONTROVERSY: DISCUSSIONS ON A \\ FINANCIAL EDUCATION FOR MATHEMATICS IN BASIC EDUCATION
}

\author{
Jéssica Ignácio de Souza ${ }^{1}$ \\ Alayde Ferreira dos Santos ${ }^{2}$
}

\begin{abstract}
Resumo: O presente trabalho tem como objetivo analisar as controvérsias jurídicas sobre o sistema Price, bem como a construção matemática da tabela, de modo a possibilitar a reflexão sobre este conteúdo que vem sendo inserido nas propostas curriculares. Utilizamos como aporte um artigo sobre a controvérsia jurídica, juntamente com as leis envolvidas e os conhecimentos matemáticos que são mobilizados para a construção da tabela Price, tendo como público-alvo os professores de matemática que atuam no Ensino Médio. Além disso, utilizamos os aportes da perspectiva Ciência, Tecnologia e Sociedade (CTS) para pensar sobre o papel dos profissionais de matemática na atual conjuntura da sociedade, para atuar no processo de preparação de seus alunos como futuros cidadãos reflexivos, atuantes e capazes. Como resultados, apresentamos como o conhecimento sobre o sistema Price e a controvérsia jurídica que o envolve pode auxiliar o indivíduo a se posicionar criticamente, bem como a tomar decisões conscientes, se trabalhado mediante discussões, exemplificações, e problematizações de questões de âmbito social.
\end{abstract}

Palavras-chave: Sistema Price; Controvérsia Jurídica; Educação Financeira.

\begin{abstract}
The present work has as objective to analyze the legal controversies about the Price system, as well as the mathematical construction of the table, in order to allow the reflection on this content that has been inserted in the curricular proposals. We use as input an article on the legal controversy, along with the laws involved and the mathematical knowledge that are mobilized for the construction of the Price table, targeting high school math teachers. In addition, we use the contributions of the Science, Technology and Society (CTS) perspective to think about the role of mathematics professionals in today's society, to act in the process of preparing their students as future reflective, active and capable citizens. As results, we present how the knowledge about the Price system and the legal controversy that surrounds it can help the individual to position himself critically, as well as to make conscious decisions, if worked through discussions, exemplifications, and problematizations of issues of social scope.
\end{abstract}

Keywords: Price system; Juridical Controversy; Financial education.

\footnotetext{
${ }^{1}$ Mestre em Educação pela Universidade Federal de Santa Catarina (UFSC). Doutoranda em Educação Científica e Tecnológica pela Universidade Federal de Santa Catarina (UFSC), Florianópolis, Santa Catarina, Brasil. E-mail: jessica isouza@ hotmail.com

${ }^{2}$ Mestre em Educação pela Université do Québec à Chicoutimi. Doutoranda em Educação Científica e Tecnológica pela Universidade Federal de Santa Catarina (UFSC), Florianópolis, Santa Catarina, Brasil e professora da Universidade do Estado da Bahia- UNEB, Senhor do Bonfim, Bahia, Brasil. E-mail: layfsantos@gmail.com
} 
DOI: http://dx.doi.org/10.33238/ReBECEM.2019.v.3.n.2.22499

\title{
1 Da Matemática Financeira para a Educação Financeira
}

Como área do conhecimento matemático, a Matemática Financeira estuda o comportamento do dinheiro no tempo, trabalhando com os conceitos de capital, tempo, juros, taxa de juros e montante. Entretanto, propostas sobre o trabalho com a Matemática Financeira nas escolas indicam que o professor deve ir além da abordagem desses conceitos, dirigindo-se para como e de que modo a Educação Financeira pode se juntar aos conteúdos da matemática que se ensina na escola.

De acordo com a Organização para a Cooperação e Desenvolvimento Econômico (OCDE) Educação Financeira é

\begin{abstract}
o processo mediante o qual os indivíduos e as sociedades melhoram a sua compreensão em relação aos conceitos e produtos financeiros, de maneira que, com informação, formação e orientação, possam desenvolver os valores e as competências necessários para se tornarem mais conscientes das oportunidades e riscos neles envolvidos e, então, poderem fazer escolhas bem informadas, saber onde procurar ajuda e adotar outras ações que melhorem o seu bem-estar. Assim, podem contribuir de modo mais consistente para a formação de indivíduos e sociedades responsáveis, comprometidos com o futuro (OCDE, 2013, p. 15).
\end{abstract}

Souza e Flores (2018) analisam a diferença na indicação de abordagem do assunto Matemática Financeira nas aulas de Matemática da Educação Básica, e mostram que a utilização do termo Educação Financeira não ocorre nos Parâmetros Curriculares Nacionais (BRASIL, 1998), mas ganha espaço na Base Nacional Comum Curricular (BNCC).

\begin{abstract}
Apesar da semelhança das indicações dos PCNs e da BNCC, sobre a abordagem de conceitos da matemática financeira, no que se refere à unidade temática e a relação que deve ser feita com outros conteúdos, como porcentagem e proporcionalidade, a educação financeira não foi citada nos PCNs, investida que ganhou espaço na BNCC. Essa aparente sutil diferença, [...] mostra um novo apelo ao professor de matemática, que não deve apenas ensinar os cálculos da matemática financeira, mas mais do que isso, precisa educar os alunos financeiramente para o consumo e o trabalho (SOUZA, FLORES, 2018, p. 254, grifos das autoras).
\end{abstract}

No documento final da BNCC, homologado pelo Ministério da Educação em dezembro de 2017 para a Educação Infantil e o Ensino Fundamental, a orientação é que nos anos finais os alunos devam dominar, além de outros assuntos, o cálculo de porcentagem, porcentagem de porcentagem, juros, descontos e acréscimos.

Outro aspecto a ser considerado nessa unidade temática [Número] é o estudo de conceitos básicos de economia e finanças, visando à educação financeira dos alunos. Assim, podem ser discutidos assuntos como taxa de juros, inflação, aplicações financeiras (rentabilidade e liquidez de um investimento) e impostos. Essa unidade temática favorece um estudo interdisciplinar envolvendo as dimensões culturais, sociais, políticas e psicológicas, além da 
DOI: http://dx.doi.org/10.33238/ReBECEM.2019.v.3.n.2.22499

econômica, sobre as questões do consumo, trabalho e dinheiro (BRASIL, 2017 , p. 267, grifo das autoras).

O documento referente ao Ensino Médio, na segunda versão, indicava que “(...) espera-se que os estudantes resolvam problemas envolvendo porcentagem em situações financeiras reais, pagamentos com cartão de crédito, financiamentos, amortizações e a tabela price, utilizando, inclusive, calculadoras ou planilhas eletrônicas" (BRASIL, 2016, p. 573). Já a versão final da BNCC para o Ensino Médio, homologada pelo MEC em dezembro de 2018, indica como habilidade a ser desenvolvida nos alunos a partir das aulas de matemática, dentre outras: interpretar criticamente situações econômicas; interpretar taxas e índices de natureza econômica (como, por exemplo, taxas de inflação); aplicar conceitos matemáticos no planejamento, na execução e na análise de ações envolvendo a utilização de aplicativos e a criação de planilhas (para o controle de orçamento familiar, simuladores de cálculos de juros simples e compostos, entre outros), para tomar decisões; resolver e elaborar problemas com funções exponenciais e logarítmicas nos quais seja necessário compreender e interpretar a variação das grandezas envolvidas, em contextos como o da Matemática Financeira, entre outros (BRASIL, 2018).

Ora, se esses assuntos, como os sistemas de amortização de empréstimos e financiamentos, precisam estar presentes no Ensino Médio, é necessário que seja propiciada ao professor de matemática uma formação tal que o prepare para refletir sobre os modos que estes são colocados em sala de aula. O sistema Price ${ }^{3}$, em específico, além de apresentar um nível de complexidade matemática maior em relação aos demais sistemas $^{4}$, envolve uma controvérsia jurídica em relação a sua legalidade. Além disso, o relatório do Banco Central do Brasil ${ }^{5}$, de 2017, indica o aumento da disseminação do uso da tabela do Price nos contratos financeiros. Sendo assim, delineamos como objetivo para este artigo, analisar as controvérsias jurídicas sobre o sistema Price, bem como a construção matemática da tabela, de modo a possibilitar a reflexão sobre este conteúdo, que vem sendo inserido nas propostas curriculares.

\footnotetext{
${ }^{3}$ Criado pelo matemático inglês Richard Price, porém foi difundido na França, fato que levou o sistema a ser conhecido também como Sistema de Amortização Francês (SAF). Sua principal característica é ter a prestação constante, desde que não haja cobrança de correções monetárias.

${ }^{4}$ A fórmula utilizada para definir o valor da prestação envolve o chamado Fator de Valor Presente (FVP), cuja dedução parte da soma dos termos de uma Progressão Geométrica. Enquanto uma tabela do Sistema de Amortização Constante (SAC), por exemplo, pode ser construída com as quatro operações básicas.

${ }^{5}$ Disponível em: https://www.bcb.gov.br/htms/estabilidade/2017_10/refAmortizacaoPrice.pdf. Acesso em: 23 maio de 2018.
} 
DOI: http://dx.doi.org/10.33238/ReBECEM.2019.v.3.n.2.22499

Para tanto, utilizaremos como aporte um artigo sobre a controvérsia jurídica, juntamente com as leis envolvidas ${ }^{6}$, e os conhecimentos matemáticos que são mobilizados para a construção da tabela Price. Como referencial teórico, utilizamos os aportes da perspectiva Ciência, Tecnologia e Sociedade (CTS). O que significa pensar que o papel dos profissionais de matemática, de forma em geral, é imprescindível e insubstituível na atual conjuntura da sociedade para atuar no processo de mudança social e na transformação de seus alunos como futuros cidadãos reflexivos, atuantes e capazes. Esse é o desafio do educador que se propõe a fazer um trabalho diferenciado e que venha convergir para a formação das novas gerações, no tocante ao consumo consciente e ao uso de uma educação financeira que venha beneficiá-lo no dia-a-dia para a tomada de decisões.

\section{Ciência, Tecnologia e Sociedade (CTS) e Matemática}

Nas últimas décadas, se discute com veemência sobre desenvolvimento científico e tecnológico e seus impactos sociais, que provocam mudanças ubíquas e constantes, cuja discussão precisa estar presente na educação, com vistas a promover práticas que atendam às necessidades postas pela sociedade contemporânea. E a matemática, que é uma ciência presente na educação em todos os níveis de ensino, se apresenta como constituidora dessas mudanças.

Diante disso, pensamos numa educação que precisa ser apresentada, discutida e realizada em prol de uma sociedade mais humanizadora. Assim, cabe ao professor não trabalhar preso à questão técnica dos conhecimentos do currículo. Mas, em benefício das questões sociais da realidade dos estudantes, como um caminho para "a construção do conhecimento reflexivo, libertador, tão necessário nos tempos em que vivemos" (BAZZO, 2016, p. 29) e não apenas um desenvolvimento centrado na formação para o mercado de trabalho, com exaltação do ter em detrimento do ser.

No viés dessa discussão, temos a abordagem temática Ciência, Tecnologia e Sociedade (CTS) surgida em meados do século XX, conforme nos apontam Auler e Bazzo (2001), Auler e Delizoicov (2001). Segundo esses autores, o movimento teve sua origem em países capitalistas como os Estados Unidos da América e alguns países Europeus, a partir de reflexões de vários educadores sobre os impactos causados pela ciência e

\footnotetext{
${ }^{6}$ Lei da Usura (BRASIL, 1933), Código de Defesa do Consumidor (BRASIL, 1990), e a Lei 4.380 (BRASIL, 1964), que trata, dentre outras coisas, sobre a escolha do sistema de amortização de empréstimos e financiamentos por parte do consumidor.
} 


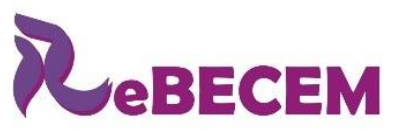

Revista Brasileira de Educação em
Ciências e Educação Matemática

DOI: http://dx.doi.org/10.33238/ReBECEM.2019.v.3.n.2.22499

tecnologia na sociedade, além de não atender ao bem-estar social. No Brasil essa discussão não é recente, porém, foram feitas reflexões para a sua implementação, levando em consideração o contexto brasileiro.

Esses autores apontaram que as discussões sobre o tema até então não condiziam com as necessidades e realidade brasileiras, isso porque segundo Auler e Bazzo (2001, p. 3) “em nosso país, a cultura de participação da sociedade em questões nacionais é bastante débil". Além disso, segundo Gana apud Auler e Bazzo (2001, p. 3) a "situação social e econômica dos países latino-americanos não é 'produto do azar'. Obedece a uma série de fatores (econômicos, históricos, culturais, políticos, entre outros) internos ao país e externos em suas relações com o resto do mundo". Não justificando assim, a utilização daqueles mesmos objetivos de implantação CTS para a realidade brasileira, além da questão dos professores que não estavam preparados para isso, ou seja, não tinham formação adequada para essa inclusão.

Contudo, os estudos e as discussões sobre essa abordagem no país foram crescendo e aos poucos, escolas e professores foram se adaptando e tentando fazer uso dessa aplicação em sala de aula. Porém, Bazzo, Pereira e Bazzo (2016, p. 75) apontam “a necessidade de uma educação mais ampla, interdisciplinar, reflexiva e crítica. Não importa a área de conhecimento", logo, a matemática faz parte desse rol. Assim, esses autores trazem o que consideram que seja CTS:

Um posicionamento epistemológico, que trata a ciência e a tecnologia como
um construto social fundamentado em aspectos humanos como prioridade
maior. Como abordagem crítica, exige, sim, atitudes diferenciadas diante do
ensino, da aprendizagem e das questões que envolvem a tecnologia e o
desenvolvimento humano (BAZZO; PEREIRA; BAZZO, 2016, p. 18).

Ao pensar na definição acima, a qualidade social da escolarização e o desenvolvimento humano é algo que precisa estar presente nas discussões mais atuais, principalmente na sala de aula de matemática, desde a formação do profissional que atua, à formação do aluno como sujeito integral. Ou seja, o movimento CTS deve vislumbrar a inserção da sociedade nos debates, além de temas científicos e tecnológicos, os de matemática, voltados para uma educação financeira, de maneira que os cidadãos sejam mais críticos e tenham mais participação nas decisões de cunho tecnocientífico. Assim, a escola não pode fugir a isso, e "o professor precisa compreender que o conhecimento científico deve estar a serviço da resolução de problemas que afligem a sociedade" (BAZZO; PEREIRA; BAZZO, 2016, p. 74). 
DOI: http://dx.doi.org/10.33238/ReBECEM.2019.v.3.n.2.22499

Percebe-se assim, que o enfoque CTS atrelado à Educação Financeira pode ser fulcral para o desenvolvimento de um ensino de matemática que faça a diferença na formação tanto dos professores quanto dos estudantes. Assim, as aulas de matemática não podem ficar restritas ao conteúdo específico, mas devem trazer elementos do contexto social como forma de desenvolvimento crítico do estudante, para que o mesmo tenha um conhecimento reflexivo acerca da matemática. Entendemos que aqui entram as discussões sobre a Matemática Financeira com o cunho primordial de Educação Financeira. Isso, por considerá-la como uma ciência crítica, de poder, como afirma Skovsmose (2001, p. 139) “a educação matemática é crítica porque desempenha um papel significante nos processos sociopolíticos [...] e pode tanto formar o cidadão de forma crítica ou não, quanto pode servir para acentuar o processo de exclusão".

Para isso, é importante apresentar os conteúdos atrelados a discussões sociais e controvérsas, de modo que o conhecimento matemático seja suporte e componha a base necessária para que os sujeitos se constituam cidadões críticos e reflexivos.

\section{A controvérsia jurídica sobre o sistema Price}

De acordo com o artigo de Neves Junior et al., (2015), os contratos de financiamentos que são realizados pelo sistema Price estão sendo questionados por meio da justiça comum, em ações revisionais de contratos. Deste modo, os autores realizaram uma pesquisa com peritos judiciais com o objetivo de verificar o entendimento dos mesmos sobre a legalidade deste sistema.

Analisando as respostas dos peritos judiciais Neves Junior et al., (2015) afirmam que é consensual que as instituições financeiras não são transparentes quanto aos juros aplicados nos contratos, bem como que há falta de compreensão dos consumidores sobre os encargos e sobre as diferenças entre os tipos de sistemas de amortização. Vale ressaltar que a falta de transparência nos contratos fere o Código de Defesa do Consumidor (BRASIL, 1990). No entanto, não há consenso entre os peritos no que se refere à cobrança de juros sobre juros, e se o Sistema Price, contraria o art. $4^{\text {o }}$ do Dec. Lei 22.626/1933 (BRASIL, 1933), a chamada Lei da Usura.

O artigo $4^{\circ}$ da Lei da Usura determina que "É proibido contar juros dos juros: esta proibição não compreende a acumulação de juros vencidos aos saldos líquidos em conta corrente de ano a ano" (BRASIL, 1993). No entanto, a legislação tem aberto exceções, 
DOI: http://dx.doi.org/10.33238/ReBECEM.2019.v.3.n.2.22499

como por exemplo, a Medida Provisória n. ${ }^{\circ}$ 2.170-36 (BRASIL, 2001), onde afirma-se no $\operatorname{artigo} 5^{\circ}$ que

\begin{abstract}
Nas operações realizadas pelas instituições integrantes do Sistema Financeiro Nacional, é admissível a capitalização de juros com periodicidade inferior a um ano.

Parágrafo único. Sempre que necessário ou quando solicitado pelo devedor, a apuração do valor exato da obrigação, ou de seu saldo devedor, será feita pelo credor por meio de planilha de cálculo que evidencie de modo claro, preciso e de fácil entendimento e compreensão, o valor principal da dívida, seus encargos e despesas contratuais, a parcela de juros e os critérios de sua incidência, a parcela correspondente a multas e demais penalidades contratuais (BRASIL, 2001, on-line).
\end{abstract}

Dos peritos judiciais participantes da pesquisa de Neves Junior et al., (2015), em sua maioria formados em contabilidade $7,65,45 \%$ concordam total ou parcialmente que existe a cobrança de juros de juros. Porém, os autores verificaram "[...] duas linhas de raciocínio. A primeira é que a Tabela Price não tem capitalização composta, não obstante utilizar a fórmula de juros compostos e, a segunda é, uma vez que a prestação se obtém pela fórmula dos juros compostos, a capitalização também é composta" (NEVES JUNIOR et al., 2015, p. 9).

Não há consenso inclusive na literatura que trata sobre o assunto. Há quem defenda que a Lei da Usura pró́be a prática de anatocismo, e que esta prática é diferente do conceito de capitalização composta. Jantalia (2012), por exemplo, afirma que o anatocismo ocorre quando os juros vencidos e não pagos são incorporados ao saldo devedor, que difere, segundo o autor, dos juros compostos, que incidem sobre o capital inicial mais os juros acumulados até o momento. Em contrapartida, para Hoog (2009) basta a capitalização composta de um capital para que a cobrança seja configurada como anatocismo.

Vale destacar também que $76,36 \%$ dos peritos judiciais discordam total ou parcialmente que os consumidores entendem os encargos do financiamento. Além disso, $84,55 \%$ discordam total ou parcialmente que os consumidores conseguem diferenciar Tabela Price de outro sistema de amortização. Este dado é alarmante, pois podemos inferir como hipótese que grande parte dos indivíduos consomem os produtos financeiros sem ter consciência de sua escolha. Inclusive, o aumento do uso do sistema Price, apontado pelo Banco Central do Brasil e já mencionado neste artigo, nos dá pistas de que essa escolha tem sido feita sem o devido conhecimento. É pouco conhecida, e talvez seja

\footnotetext{
${ }^{7}$ Dos 110 respondentes, $88,18 \%$ são formados em Contabilidade, e os demais possuem graduação em Administração $(3,64 \%)$ e Economia $(8,18 \%)$ (NEVES JUNIOR et al., 2015).
} 
DOI: http://dx.doi.org/10.33238/ReBECEM.2019.v.3.n.2.22499

omitida pelas instituições financeiras de forma proposital, a Lei no 4380 (BRASIL, 1964), a qual infere sobre a escolha do sistema de amortização de empréstimos e financiamentos. $\mathrm{O}$ artigo 15-B determina que nestas operações poderão ser livremente pactuada entre as partes, sendo que

§ 3o Nas operações de empréstimo ou financiamento de que dispõe o caput é obrigatório o oferecimento ao mutuário do Sistema de Amortização Constante - SAC e de, no mínimo, outro sistema de amortização que atenda o disposto nos $\S \S 1$ o e 2oㅡㄹ entre eles o Sistema de Amortização Crescente - SACRE e o Sistema Francês de Amortização (Tabela Price) (BRASIL, 1964, on-line).

Emerge das questões apresentadas neste tópico a necessidade de se problematizar estas questões em sala de aula quando da abordagem de assuntos da Matemática Financeira, numa perspectiva de Educação Financeira.

Dependendo da forma como é desenvolvido em sala de aula, o conhecimento matemático pode subsidiar os indivíduos na capacidade de leitura e inferência diante desse mundo marcado pelo desenvolvimento científico e tecnológico, mas que traz grandes dilemas sociais. E essa compreensão é fundamental para que o aluno entenda a relação com o mundo a sua volta, ou seja, não apenas ter o domínio dos conhecimentos científicos, mas que desenvolva outros saberes necessários à sua capacidade de discernimento. Assim, "valorizamos o saber com, e não, simplesmente, o saber sobre, que sempre, se quer universal e assim se descola das especificidades do contato com a vida" (PORTO-GONÇALVES, 2017, p. 456).

\section{A construção da tabela Price}

É comum a caracterização do sistema de amortização de empréstimos e financiamentos Price como sendo aquele que possibilita a devolução do capital mais os juros mediante prestações constantes. De fato, o primeiro passo para a construção da Tabela é calcular a prestação, que tem o mesmo valor para cada parcela no período de devolução. Porém, o que deve ficar explícito ao consumidor é que na maioria dos contratos ocorre a correção monetária, ou seja, a atualização do valor da prestação através dos índices da inflação.

A fórmula para obtenção do valor da prestação provém da soma do Valor Presente $^{8}$ dos termos, na data zero, conforme Figura 1.

\footnotetext{
${ }^{8}$ Utilizado com PV em produções da área e na calculadora financeira HP-12C, que remete à expressão em inglês Present Value.
} 
Figura 1: Fluxo de caixa sob o ponto de vista do cliente

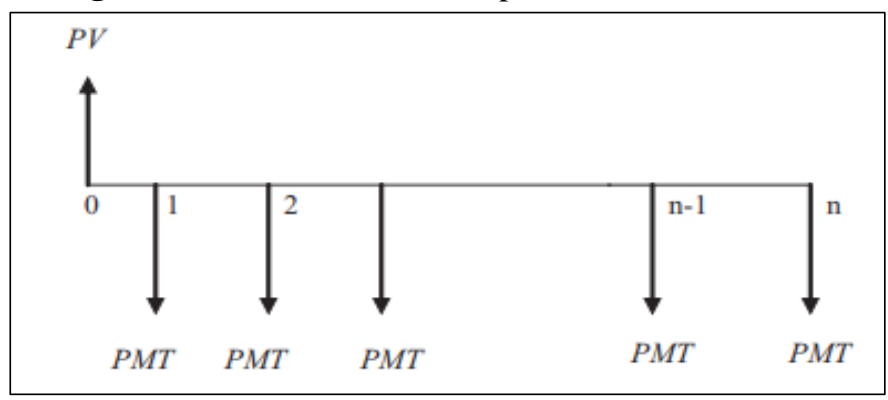

Fonte: Guerra e Taneja (2009)

Para tanto, utiliza-se a fórmula do Montante Composto $\left(M=C(1+i)^{n}\right)^{9}$ para cada um dos termos, conforme a seguir.

$$
P V=\frac{P M T}{(1+i)}+\frac{P M T}{(1+i)^{2}}+\frac{P M T}{(1+i)^{3}}+\ldots+\frac{P M T}{(1+i)^{n}}
$$

Colocando PMT em evidência, temos

$$
P V=P M T \cdot\left[\frac{1}{(1+i)}+\frac{1}{(1+i)^{2}}+\frac{1}{(1+i)^{3}}+\ldots+\frac{1}{(1+i)^{n}}\right]
$$

Ao termo destacado, chamamos de "a $n$, cantoneira, $i$ ”, para, a partir deste, definirmos o Fator de Valor Presente (FVP). Este fator é definido pela expressão que define a soma dos termos da Progressão Geométrica (PG), onde $a_{1}$ é o primeiro termo, $a_{n}$ o último, e $q$ a razão da PG.

$$
S_{n}=\frac{a_{1}-a_{n} * q}{1-q}
$$

Substituindo os termos, temos como FVP:

$$
a_{n_{i}}=\frac{1-(1+i)^{-n}}{i}
$$

Desse modo, o valor presente de uma série de pagamentos é definido por:

$$
P V=P M T * a_{n_{i}}
$$

\footnotetext{
${ }^{9}$ Onde $C$ é o capital (emprestado ou financiado), $M$ é o montante (capital mais juros), $i$ é a taxa de juros e $n$ é o período. Utilizaremos $P M T$ para o valor da prestação, que em inglês significa Periodic Payment Amount, ou seja, valor do pagamento periódico.
} 


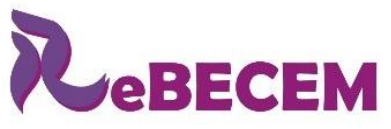

Revista Brasileira de Educação em

Ciências e Educação Matemática

ISSN 2594-9179

Como o interesse no sistema Price é o cálculo da prestação, basta dividir o PV, ou seja, o valor financiado ou emprestado, pelo FVP.

$$
P M T=\frac{P V}{a_{n_{i}}}
$$

Para a construção da planilha, após determinar o valor da prestação, calcula-se os juros do primeiro período (taxa de juros multiplicada pelo saldo devedor inicial), e subtrai-se este valor da prestação a fim de determinar a amortização. Após atualizar o saldo devedor, ou seja, descontar a amortização determinada, os juros do período seguinte são calculados. Então, as operações são repetidas até o último período, quando o saldo devedor é zerado. Neste sistema, a amortização é crescente em Progressão Geométrica de razão $1+i$, e o juro é decrescente.

No Quadro 1, apresentamos um exemplo da tabela Price a partir de uma situação hipotética. O exemplo ilustra uma situação de empréstimo de $120.000 \mathrm{UM}^{10}$, com taxa de juros de 2,5\% ao mês, e o prazo de 12 meses, sem correção monetária.

\begin{tabular}{|c|c|c|c|c|}
\hline Quâs & Saldo devedor & Amortização & Juros & Prestação \\
\hline 0 & $120.000,00$ & - & - & - \\
\hline 1 & $111.301,54$ & $8.698,46$ & $3.000,00$ & $11.698,46$ \\
\hline 2 & $102.385,63$ & $8.915,92$ & $2.782,54$ & $11.698,46$ \\
\hline 3 & $93.246,81$ & $9.138,81$ & $2.559,64$ & $11.698,46$ \\
\hline 4 & $83.879,53$ & $9.367,28$ & $2.331,17$ & $11.698,46$ \\
\hline 5 & $74.278,06$ & $9.601,47$ & $2.096,99$ & $11.698,46$ \\
\hline 6 & $64.436,56$ & $9.841,50$ & $1.856,95$ & $11.698,46$ \\
\hline 7 & $54.349,02$ & $10.087,54$ & $1.610,91$ & $11.698,46$ \\
\hline 8 & $44.009,29$ & $10.339,73$ & $1.358,73$ & $11.698,46$ \\
\hline 9 & $33.411,06$ & $10.598,22$ & $1.100,23$ & $11.698,46$ \\
\hline 10 & $22.547,89$ & $10.863,18$ & 835,28 & $11.698,46$ \\
\hline 11 & $11.413,13$ & $11.134,76$ & 563,70 & $11.698,46$ \\
\hline 12 & 0 & $11.413,13$ & 285,33 & $11.698,46$ \\
\hline Total & & $120.000,00$ & $\mathbf{2 0 . 3 8 1 , 4 6}$ & $\mathbf{1 4 0 . 3 8 1 , 4 6}$ \\
\hline
\end{tabular}

Fonte: Elaborado pelas autoras, 2018

No Quadro 2, a mesma situação é aplicada para o Sistema de Amortização Constante (SAC), para comparação.

Quadro 2: Exemplo de tabela SAC.

\begin{tabular}{|c|c|c|c|c|}
\hline Mês & Saldo devedor & Amortização & Juros & Prestação \\
\hline 0 & $120.000,00$ & - & - & - \\
\hline 1 & $110.000,00$ & $10.000,00$ & $3.000,00$ & $13.000,00$ \\
\hline
\end{tabular}

\footnotetext{
${ }^{10}$ Unidade Monetária.
} 
DOI: http://dx.doi.org/10.33238/ReBECEM.2019.v.3.n.2.22499

\begin{tabular}{|r|c|c|c|c|}
\hline 2 & $100.000,00$ & $10.000,00$ & $2.750,00$ & $12.750,00$ \\
\hline 3 & $90.000,00$ & $10.000,00$ & $2.500,00$ & $12.500,00$ \\
\hline 4 & $80.000,00$ & $10.000,00$ & $2.250,00$ & $12.250,00$ \\
\hline 5 & $70.000,00$ & $10.000,00$ & $2.000,00$ & $12.000,00$ \\
\hline 6 & $60.000,00$ & $10.000,00$ & $1.750,00$ & $11.750,00$ \\
\hline 7 & $50.000,00$ & $10.000,00$ & $1.500,00$ & $11.500,00$ \\
\hline 8 & $40.000,00$ & $10.000,00$ & $1.250,00$ & $11.250,00$ \\
\hline 9 & $30.000,00$ & $10.000,00$ & $1.000,00$ & $11.000,00$ \\
\hline 10 & $20.000,00$ & $10.000,00$ & 750,00 & $10.750,00$ \\
\hline 11 & $10.000,00$ & $10.000,00$ & 500,00 & $10.500,00$ \\
\hline 12 & 0 & $10.000,00$ & 250,00 & $10.250,00$ \\
\hline Total & & $120.000,00$ & $\mathbf{1 9 . 5 0 0 , 0 0}$ & $\mathbf{1 3 9 . 5 0 0 , 0 0}$ \\
\hline
\end{tabular}

Fonte: Elaborado pelas autoras, 2018.

Os juros a serem pagos nesta situação com a operação feita pelo sistema Price é 881,46 UM a mais em comparação com o SAC. Esta simulação foi feita com um período de 12 meses, porém os financiamentos são feitos, geralmente, para pagamento durante anos, o que aumentaria ainda mais essa diferença. A incidência de juros no Price é maior devido à cobrança de juros compostos, e é possível perceber pelo Quadro 1 que a amortização mais baixa no início faz com que o saldo devedor diminua menos nos primeiros períodos e, consequentemente, os juros serão mais altos.

No entanto, as primeiras prestações do SAC ficam maiores, por conta de maior valor de amortização. Enquanto a primeira prestação do SAC ficou em 13.000 UM, a do Price, que é constante na simulação sem correção monetária, é de 11.698,46 UM, o que pode atrair os consumidores que não estão aptos a compararem todo o processo, e que não estejam conscientes da diferença que terão de pagar por optarem pelo Price. Soma-se a isso, o não conhecimento da Lei $n^{\circ} 4380$ (BRASIL, 1964), que permite às partes pactuarem a escolha do sistema.

Cabe problematizar a questão da correção monetária. Pois, conforme mencionado, essa atualização faz com que a prestação do Price não seja mais constante. No Quadro 3, mostramos a situação apresentada no Quadro 1, porém com os valores atualizados de acordo com índices inflacionários ${ }^{11}$. Para tanto, calculamos as taxas acumuladas ${ }^{12}$ para cada período e atualizamos o valor das prestações.

\footnotetext{
${ }^{11}$ Os índices mais utilizados são o Índice Geral de Preços do Mercado (IGP-M), Índice Nacional de Preços ao Consumidor (INPC) e a Taxa Referencial (TR). Os percentuais utilizados para a construção da tabela foram simulações retiradas de Guerra e Taneja (2009).

${ }^{12}$ Para o cálculo da taxa acumulada: $i_{\text {Acumulada }}=\left[\left(1+i_{1}\right) *\left(1+i_{2}\right) * \ldots *\left(1+i_{n}\right)\right]-1$.
} 
DOI: http://dx.doi.org/10.33238/ReBECEM.2019.v.3.n.2.22499

Quadro 3: Exemplo de tabela Price com correção monetária.

\begin{tabular}{|c|c|c|c|}
\hline Mês & Índices & Acumulada & Prestação \\
\hline 0 & & & - \\
\hline 1 & $1,30 \%$ & $1,30 \%$ & $11.850,54$ \\
\hline 2 & $1,50 \%$ & $2,82 \%$ & $12.028,29$ \\
\hline 3 & $1,70 \%$ & $4,57 \%$ & $12.232,77$ \\
\hline 4 & $1,90 \%$ & $6,55 \%$ & $12.465,20$ \\
\hline 5 & $1,80 \%$ & $8,47 \%$ & $12.689,57$ \\
\hline 6 & $2,00 \%$ & $10,64 \%$ & $12.943,36$ \\
\hline 7 & $2,10 \%$ & $12,97 \%$ & $13.215,17$ \\
\hline 8 & $2,30 \%$ & $15,56 \%$ & $13.519,12$ \\
\hline 9 & $1,75 \%$ & $17,59 \%$ & $13.755,71$ \\
\hline 10 & $2,20 \%$ & $20,17 \%$ & $14.058,33$ \\
\hline 11 & $1,30 \%$ & $21,73 \%$ & $14.241,09$ \\
\hline 12 & $1,20 \%$ & $23,20 \%$ & $14.411,98$ \\
\hline Total & & & $\mathbf{1 5 7 . 4 1 1 , 1 4}$ \\
\hline
\end{tabular}

Fonte: Elaborado pelas autoras, 2018.

Para empréstimos e financiamentos com prazo superior a um ano "Existem empresas que diluem a correção mensalmente, outras a cada ciclo de um ano [...]." (GIMENES, 2002, p. 88). É importante o consumidor estar ciente, portanto, que a prestação no Price será crescente, caso haja previsão de correção monetária no contrato.

Ao atualizar os valores das prestações da tabela SAC pelos mesmos índices, a diferença do total pago pelo empréstimo aumenta para 1.737,24 UM.

Discutir sobre educação financeira com os alunos da educação básica parece ser mais uma das funções atribuídas ao professor de matemática, em especial do Ensino Médio. Sendo assim, torna-se necessário fazer com que os estudantes a utilizem como elemento motivador para o enfrentamento de situações diárias que requeiram o uso dos conteúdos de Matemática Financeira, de forma consciente e prática. Cabe ao professor, portanto, fazer uso de discussões, exemplificações e problematizações de questões de âmbito social, ou seja, trabalhar os conteúdos matemáticos considerando as controvérsias envolvidas nos diversos âmbitos da sociedade, seja do campo da ciência, do jurídico ou da economia.

Campos (2012) alerta para a possibilidade que a Educação Financeira tem de se tornar uma ferramenta de marketing ao analisar documentos da Organização para a Cooperação e Desenvolvimento Econômico (OCDE), que apresentam orientações sobre educação financeira. $\mathrm{O}$ autor afirma que

[...] percebemos o texto sinalizando para um grande potencial de ampliação de produtos financeiros, como: planos de previdência aberta, capitalização ou mercado de seguros. Assim, o documento afirma que a inserção da educação 


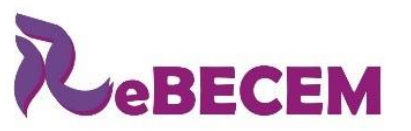

Revista Brasileira de Educação em

Ciências e Educação Matemática

DOI: http://dx.doi.org/10.33238/ReBECEM.2019.v.3.n.2.22499

financeira pode também "propiciar a inserção de novos e potenciais consumidores que, por desconhecimento e dificuldades de acesso a informações especializadas nunca operaram nesses mercados". [...] Esta observação aponta para a percepção de outro mercado com grande potencial de ampliação (CAMPOS, 2012, p. 27).

Nesse sentido, a inserção da Educação Financeira que vem sendo proposta para a matemática escolar deve ser problematizada, pois ao invés de ser um modo de controle das ações dos indivíduos para o bom funcionamento da economia, ou uma maneira de captar novos consumidores para o mercado financeiro, deve dar possibilidade aos indivíduos de se posicionarem frente a situações que enfrentarão nas esferas políticas, econômicas e sociais.

O trabalho com a problematização das controvérsias envolvidas no sistema Price permite o entendimento de que os conceitos matemáticos, como os da Matemática Financeira, apesar de permeados por objetividades e racionalidades, precisam ser compreendidos de modo que se possa estar apto a lidar com outros entraves da esfera social. A inclusão de tópicos da Matemática Financeira, como os sistemas de amortização de empréstimos e financiamentos, envolve diversos conteúdos matemáticos como porcentagem, equações e funções exponenciais, progressões aritméticas (Sistema SAC) e geométricas (sistema Price). Ao apresenta-los numa perspectiva de Educação Financeira relacionando-os com questões políticas, econômicas e sociais como a controvérsia jurídica, possibilita-se a formação de sujeitos que tenham um posicionamento crítico, reflexivo e embasado.

\section{Considerações finais}

Conforme exposto neste artigo, não há consenso, tanto na literatura quanto na opinião de peritos judiciais, no que se refere à legalidade do sistema Price e, até mesmo, ao fato do sistema envolver a cobrança de juros compostos, ou se esse tipo de capitalização configura anatocismo. Além disso, é consensual entre os peritos que a população não entende os encargos do financiamento e não sabem diferenciar o Price de outros sistemas de amortização de empréstimos e financiamentos.

Torna-se importante, portanto, que ao inserir conteúdos da Matemática Financeira, numa perspectiva de Educação Financeira, conforme vem sendo proposto por documentos curriculares, questões como a abordada neste artigo sejam problematizada, com vistas à formação de indivíduos preparados para se posicionar frente a situações financeiras, e tomar decisões de modo crítico e consciente. 


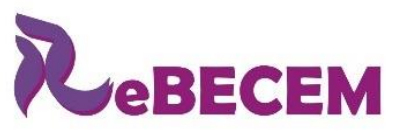

Revista Brasileira de Educação em

Ciências e Educação Matemática

ISSN 2594-9179

DOI: http://dx.doi.org/10.33238/ReBECEM.2019.v.3.n.2.22499

O conhecimento matemático sobre o sistema Price, desde a dedução de sua

fórmula que envolve equações exponenciais e progressão aritmética, permite concluir que este envolve a cobrança de juros compostos. A compreensão de que a prestação será constante apenas antes da atualização dos valores pela correção monetária possibilita a melhoria no planejamento financeiro. $\mathrm{O}$ entendimento de todo o processo de construção da tabela Price, bem como do comparativo entre os sistemas de amortização prepara o indivíduo para escolhas conscientes e embasadas matematicamente.

Sendo assim, o ensino da Matemática Financeira deve problematizar as questões políticas, econômicas e sociais envolvidas nos seus conteúdos, e no caso específico dos professores do Ensino Médio, cabe trabalhar com as questões abordadas no presente artigo.

\section{Referências}

AULER, D.; BAZZO, W. A. Reflexões para a implementação do Movimento CTS no Contexto Educacional Brasileiro. Ciência e Educação, São Paulo, v. 7, n.1, p. 1-13, 2001.

AULER, D.; DELIZOICOV, D. Alfabetização Científico-Tecnológica Para Quê? Revista Ensaio, Belo Horizonte, v.3, n. 2, p.122-134, jul./dez. 2001.

BAZZO, W.A.; PEREIRA, L. T. V.; BAZZO, J. L. S. Conversando sobre Educação Tecnológica. 2. ed. Florianópolis: Ed. da UFSC, 2016.

BAZZO, W. A. Ponto de Ruptura Civilizatória: a Pertinência de uma Educação "Desobediente". Revista CTS, Argentina, v. 11, n. 33, p. 73-91, set. 2016.

BRASIL. Congresso Nacional. Decreto-Lei no 22.626, de 7 de abril de 1933. Dispõe sobre os juros nos contratos e dá outras providências. Brasília, 1933. Disponível em: http://www.planalto.gov.br/ccivil_03/decreto/d22626.htm. Acesso em: 6 jun. 2018.

BRASIL. Congresso Nacional. Lei no 4.380, de 21 de agosto de 1964. Institui a correção monetária nos contratos imobiliários de interêsse social, o sistema financeiro para aquisição da casa própria, cria o Banco Nacional da Habitação (BNH), e Sociedades de Crédito Imobiliário, as Letras Imobiliárias, o Serviço Federal de Habitação e Urbanismo e dá outras providências. Brasília, 1964. Disponível em: http://www.planalto.gov.br/ccivil_03/LEIS/L4380.htm. Acesso em: 8 ago. 2018.

BRASIL. Congresso Nacional. Lei no 8.078, de 11 de setembro de 1990. Dispõe sobre a proteção do consumidor e dá outras providências. Brasília, 1990. Disponível em: http://www.planalto.gov.br/ccivil_03/Leis/18078.htm. Acesso em: 6 jun. 2018.

BRASIL. Ministério da Educação. Parâmetros Curriculares Nacionais (PCNs). Matemática. Ensino Fundamental. Terceiro e quarto ciclos. Brasília: MEC/SEF, 1998.

BRASIL. Congresso Nacional. Medida Provisória N 2.170-36, de 23 de agosto de 2001. Dispõe sobre a administração dos recursos de caixa do Tesouro Nacional, consolida e atualiza a legislação pertinente ao assunto e dá outras providências. Brasília, 2001. 


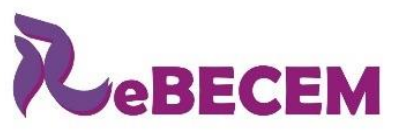

Revista Brasileira de Educação em

Ciências e Educação Matemática

ISSN 2594-9179

DOI: http://dx.doi.org/10.33238/ReBECEM.2019.v.3.n.2.22499

BRASIL. Ministério da Educação. Base Nacional Curricular Comum. $2^{\mathrm{a}}$ versão. Brasília: MEC, 2016. Disponível em: http://basenacionalcomum.mec.gov.br/documentos/bncc-

2versao.revista.pdf. Acesso em: 31 jul. 2016.

BRASIL. Ministério da Educação. Base Nacional Curricular Comum. Versão Final. Brasília: MEC, 2017. Disponível em:

http://basenacionalcomum.mec.gov.br/images/BNCC_20dez_site.pdf. Acesso em: 9 fev. 2018.

BRASIL. Ministério da Educação. Base Nacional Comum Curricular. Brasília: MEC, 2018. Disponível em: http://basenacionalcomum.mec.gov.br/wp-

content/uploads/2018/12/BNCC_19dez2018_site.pdf. Acesso em: 5 fev. 2019.

CAMPOS, M. B. Educação financeira na matemática do ensino fundamental: uma análise de produção de significado. 2012. Dissertação (Mestrado Profissional em Educação Matemática) - Faculdade de Educação, Universidade Federal de Juiz de Fora, Juiz de Fora, 2012.

GIMENES, C. A correção monetária no financiamento de imóveis. Pensamento e realidade, São Paulo, v. 5, n. 11, p. 82-110, 2002.

GUERRA, F.; TANEJA, I. J. Matemática Financeira. Curso de graduação em Administração a Distância. 1. ed. Florianópolis: UFSC, 2009.

HOOG, W. A. Z. Prova Pericial Contábil: aspectos práticos e fundamentais.

7. ed. Curitiba: Juruá, 2009.

JANTALIA, F. Juros bancários. 1. ed. São Paulo: Atlas, 2012.

NEVES JUNIOR, I. J. das. et al. A capitalização dos juros na Tabela Price no entendimento dos peritos judiciais que atuam na região Sudeste do Brasil. In: CONGRESSO DE

CONTABILIDADE, 6., 2015, Florianópolis. Anais... Florianópolis: UFSC, 2015. p. 1-16.

OCDE. La educación financeira en América Latina y el Caribe: situación actual y perspectivas. OCDE, [S.I.], 2013. Disponível em: https://www.oecd.org/daf/fin/financialeducation/OECD_CAF_Financial_Education_Latin_AmericaES.pdf. Acesso em: 27 fev. 2017.

PORTO-GONÇALVES, C. W. A globalização da natureza e a natureza da globalização. 7 ed. Rio de Janeiro: Civilização Brasileira, 2017.

SKOVSMOSE, O. Educação Matemática Crítica: a questão da democracia. Tradução de Abgail Lins e Jussara de Loiola Araújo. 1. ed. Campinas: Papirus, 2001.

SOUZA, J. I.; FLORES, C. R. Educación matemática financiera en la escuela: a propósito de prácticas discursivas para la historia de un saber. Revista Paradigma, Venezuela, v. 34, n. extra 1, p. 249-264, 2018.

Recebido em: 28 de maio de 2019.

Aceito em: 13 de agosto de 2019. 